\title{
REFUGIADOS: QUESTÕES POLÍTICAS, JURÍDICAS E SOCIAIS
}

\author{
REFUGEES: POLTITIC, JURIDIC AND SOCIAL ISSUES
}

\author{
Anderson Domingos* \\ Maria Geralda de Miranda**
}

\begin{abstract}
Resumo: O aumento dos conflitos no mundo e as violações de direitos, principalmente nos países subdesenvolvidos, continuam fazendo com que populações inteiras tenham que deixar a terra de origem para escapar da fome e de contínuas atrocidades. Este estudo, por meio de pesquisa bibliográfica e documental, busca refletir sobre a situação das pessoas em situação de refúgio. Faz uma breve explanação acerca da legislação internacional e do contexto que a motivou. A seguir aborda a situação do Brasil no que tange à proteção aos refugiados e, por fim, debate a problemática do refúgio e conclui que a garantia dos direitos humanos dos refugiados faz parte de um grande desafio, que deve ser enfrentado uma vez que esse direito já foi violado, quando da fuga do indivíduo de seu país de origem.
\end{abstract}

Palavras-Chave: Direitos Humanos. Pessoas vulneráveis. ONU.

Abstract: The increase in conflicts in the world and violations of rights, especially in the underdeveloped countries continue to cause entire populations to leave their homeland to escape hunger and continuous atrocities. This study, through bibliographical and documentary research, seeks to reflect on the situation of people in situations of refuge. It gives a brief explanation of international law and the context that motivated it. It then discusses Brazil's situation with regard to refugee protection and, finally, discusses refugee issues and concludes that guaranteeing the human rights of refugees is a major challenge, which must be tackled as this right was already violated when the individual fled from his country of origin.

Keywords: Human rights. Vulnerable people. UN.

\footnotetext{
* Mestre em Desenvolvimento Local pelo Centro Universitário Augusto Motta - UNISUAM. Pósgraduado em Direito Público pela Universidade Iguaçu. Graduado em Direito pela Universidade Iguaçu. É professor da Universidade Iguaçu.

** Pós-doutora em Políticas Públicas, Pesquisadora do Programa de Pós-graduação em Desenvolvimento Local, Centro Universitário Augusto Motta. E-mail: mgeraldamiranda@gmail.com.
} 


\section{INTRODUÇÃO}

O Alto Comissariado das Nações Unidas para Refugiados (ACNUR), define refugiados como sendo pessoas que estão fora de seu país de origem devido a fundados temores de perseguição relacionados a questões de raça, religião, nacionalidade, pertencimento a um determinado grupo social ou opinião política, como também devido à grave e generalizada violação de direitos humanos e conflitos armados.

Já Piovesan (2012, p. 49) define refugiado como pessoa que não só não é respeitada pelo Estado ao qual pertence como também é esse Estado quem a persegue, ou não pode protegê-la, caso esteja sendo perseguida.

Em razão da Segunda Guerra Mundial, houve um grande deslocamento humano, alcançando o número de 40 milhões de pessoas saídas da Europa, além de terem saído 13 milhões de alemães dos países que formavam a União das Repúblicas Socialistas Soviéticas, URSS. (ALTO COMISSARIADO DAS NAÇÕES UNIDAS PARA REFUGIADOS, 2002). Este grande deslocamento passou a exigir que normas fossem estabelecidas para garantir que os direitos humanos desses refugiados fossem levados em consideração da mesma forma que o da população nativa de um determinado Estado.

Com sede em Genebra, o ACNUR surgiu com o objetivo de auxiliar na solução do problema do crescente número de pessoas que necessitam de amparo e que não tem como recorrer à proteção de seu país de origem, como é o caso dos refugiados.

Assim, esta entidade da Organização das nações Unidas, ONU, trabalha buscando assegurar permanência para refugiados em outros Estados. As suas ações só são possíveis por causa dos tratados internacionais e das relações entre países para que pessoas submetidas à condição de refugiado possam ser acolhidas de maneira humanitária e solidária.

Mas mesmo com os esforços para oferecer auxílio aos refugiados, a situação deles tem se transformado em uma crise humanitária de proporções mundiais, deixando clara a falta de vontade e suporte por parte de governos para que 
legislações, planos e ações destinados a ajudar os refugiados, sejam efetivos e apresentem resultados positivos.

\section{O REFÚGIO E A LEGISLAÇÃO INTERNACIONAL}

A Declaração Universal dos Direitos Humanos da ONU, que completa 70 anos em 2018, é, até hoje, uma das mais importantes ferramentas de globalização dos direitos humanos, mesmo sofrendo com processos constantes de avanço e retrocesso na manutenção desses direitos, uma vez que conflitos motivados por diferenças políticas, religiosas e sociais não podem ser eliminados apenas com a constatação de um direito inerente aos indivíduos.

Junto com os mecanismos convencionais, os Direitos Humanos contam ainda com procedimentos especiais, conhecidos como Relatores Especiais ou Especialistas Independentes, num total de 44 procedimentos até o momento, que são mecanismos de inquérito e monitoramento independentes do Conselho da ONU, focados em avaliar contextos específicos de casos que possam estar violando os direitos humanos por meio de mandatos centrados em temas específicos, além de 12 mandatos de países.

Além dessas ferramentas, a Organização das Nações Unidas possui, ainda, o Escritório do Alto Comissariado das Nações Unidas para os Direitos Humanos, entidade que tem como principal responsabilidade a promoção, coordenação, disseminação e fortalecimento dos direitos humanos dentro do sistema da própria ONU.

À medida que a Declaração Universal dos Direitos Humanos da ONU se desenvolve e ganha mais mecanismos e entidades para promover suas diretrizes, maior a sua efetividade. Por este motivo, a própria ONU tem ampliado seu alcance, contando com diversos escritórios, centros regionais e acessórias em todo o mundo, trabalhando em parceria com organizações da sociedade civil e contando com o apoio dos governos para resguardar e fazer cumprir os direcionamentos que asseguram os direitos humanos. 
Entender a forma como a legislação internacional de proteção aos direitos humanos dos refugiados se concretizou se relaciona com o desenvolvimento da própria Organização das Nações Unidas, ONU, e de suas comissões e direcionamentos, bem como com a Declaração Universal dos Direitos Humanos.

No final da década de 1940, em meio aos problemas ocorridos com a construção do Muro de Berlim e a Guerra da Coréia, a Assembleia Geral da ONU determinou a criação do Alto Comissariado das Nações Unidas para os Refugiados, ACNUR, que deu início às suas ações efetivamente em $1^{\circ}$ de janeiro de 1951.

As atividades desse Alto Comissariado relacionam-se à elaboração de programas de assistência especialmente voltados a determinados grupos, tais como crianças e os idosos, e também aos refugiados, abarcando os apátridas, os migrantes internos e os solicitantes de refúgios.

Além disso, a ONU também criou em 1951 a Convenção Relativa ao Estatuto dos Refugiados, especificamente para a proteção desse grupo de pessoas, passando a viger em 21 de abril de 1954. Já nas décadas de 1960 e de 1970 ocorreram muitos movimentos nacionalistas, dentro das colônias asiáticas e africanas, o que desencadeou a descolonização dessas nações e a concretização de novos Estados, tendo alguns países conquistado a independência por meio de conflitos violentos, tais como o Paquistão e a Ruanda (SARAIVA, 1997, p. 87).

Em razão dos diversos movimentos asiáticos e africanos de independência, surgiu um novo instrumento de proteção dos refugiados, denominado de Protocolo sobre o Estatuto dos Refugiados, o que terminou com a reserva temporal da Convenção (ANDRADE, 1996a).

Nos anos de 1970 e 1980, alguns países latino-americanos tiveram regimes de exceção, ocorrendo, assim, muitos conflitos armados, principalmente por razões políticas, o que causou uma migração de cerca de 2 milhões de refugiados advindos desses países (ANDRADE 1996a).

Com o fim da Guerra Fria, quando ocorreram muitas mudanças econômicas, sociais e políticas ao redor do mundo, o cenário econômico passou a ser representado pelo neoliberalismo e pela formação de blocos econômicos. Após a recessão econômica é que os refugiados passaram a ser vistos de maneira 
depredatória, pois eles não davam benefícios aos países desenvolvidos (FELLER, 2001). Por conseguinte, os refugiados, depois do fim da Guerra Fria, perderam o simbolismo político que tinham no período da guerra. (HYNDMAN, 2000).

\section{BRASIL E A PROTEÇÃO AOS REFUGIADOS}

O Brasil costuma ser visto como um país que recebe, de forma positiva, os refugiados. Depois da Segunda Guerra Mundial, em um contexto de idealização e estabelecimento de regimes de proteção aos direitos humanos, o Brasil desenvolveu instrumentos de proteção aos refugiados antes da ascensão do Regime Militar, como, por exemplo, a ratificação da Convenção sobre os Refugiados de 1951 (DOMINGUEZ; BEANINGER, 2007) e a participação como membro originário do Alto Comissariado das Nações Unidas para os Refugiados (MOREIRA, 2007, p. 88).

O Brasil passou a ser um país resistente e reativo à chegada de refugiados com a implantação do Regime Militar em 1964, tendo se tornado, assim, um Estado emissor de pessoas (MOREIRA, 2007, p. 89). Tendo em vista um cenário político de forte repressão, o país deixou de acolher imigrantes advindos de países da América Latina que tentavam escapar de regimes autoritários e ditatoriais (MOREIRA, 2007, p. 53).

Nesse sentido, as delegações brasileiras passaram a adotar um posicionamento ofensivo nos fóruns internacionais sobre os refugiados, obtendo muitas críticas por parte de diferentes órgãos, tais como a Corte Interamericana de Direitos Humanos da Organização dos Estados Americanos, a Anistia Internacional, a Igreja Católica de Roma e o próprio governo dos Estados Unidos da América (SILVA, 2011, p. 76).

A prática mais comum era o recebimento de visto de turista por parte dos imigrantes latino-americanos que estavam sendo perseguidos, o qual valia por apenas noventa dias e tinha como origem um pacto feito entre o ACNUR e o governo brasileiro (MOREIRA, 2007).

Assim, o Brasil acabou se tornando um país de passagem, e não exatamente de destino, no qual as pessoas refugiadas ficavam enquanto esperavam serem 
realocados em outros países (MOREIRA, 2007, p. 45). Ao mesmo tempo, entretanto, verificou-se que houve maior engajamento nas questões relacionadas a determinados setores da sociedade civil, especialmente aqueles relacionados com a Igreja Católica Romana.

Desse modo, mesmo em um contexto político de repressão e de autoritarismo, tornou-se possível adotar um plano de proteção aos refugiados, tendo em vista a limitação oferecida pela conceituação usada na época, a qual passou por transformação somente depois da redemocratização brasileira.

Alguns avanços foram realizados na política para os refugiados durante 0 período de transição entre o governo militar e o governo democrático, principalmente em razão da Declaração de Cartagena sobre Refugiados, advinda do embate de especialistas e de representantes de dez países da América Latina, e que passou a fazer parte do ordenamento jurídico brasileiro.

A Convenção que determina os direitos internacionais dos refugiados em 1951 só foi aderida pelo Brasil em 1960. Mesmo assim, apenas vinte anos depois foi instaurado um escritório do ACNUR na América Latina. Isso porque, o período que vai da década de 60 até a década de 80 foi muito marcado por regimes políticos militares e que criavam um contexto em que não era possível receber imigrantes.

A instauração do ACNUR no Brasil, neste contexto inicial, se colocou como uma forma de, em parceria com igrejas católicas, auxiliar na retirada para refúgio no exterior de brasileiros, uma forma de protegê-los das perseguições que aconteciam no momento político vivenciado no país.

Assim, o desenvolvimento de políticas para a proteção internacional foi mais demorado, uma vez que o país vivia um movimento contrário, não recebendo imigrantes refugiados, mas enviando cidadãos para se refugiarem em lugares onde a ditadura não os pudesse alcançar.

Mesmo assim, não eram raros os casos de refugiados de países vizinhos, onde aconteciam os mesmos tipos de perseguições, virem se refugiar em território brasileiro, principalmente em decorrência da proximidade e da incapacidade, seja por falta de poder aquisitivo ou de documentação, de alcançar países mais distantes. 
Principalmente a partir de 1975, a presença e auxilio das Cáritas Arquidiocesanas de São Paulo e Rio de Janeiro ganha maior destaque, estendendo assistência para o acolhimento em território nacional de pessoas vindas da Argentina, Chile e Uruguai, entre outros lugares, que enfrentavam o perigo de, caso fossem descobertos, serem enviados de volta para seus países de origem pela falta de suporte legislativo aos refugiados no Brasil.

Uma vez encerrado o período militar, no início dos anos 1980, o Brasil entra em um processo de redemocratização e, consequentemente, passa a receber cada vez mais refugiados em seu território. Agora, mais do que cidadãos de países vizinhos, o país começa a receber, também, os refugiados angolanos, que buscavam escapar da Guerra Civil que a Angola enfrentava.

Com o crescimento da necessidade de possuir estrutura para receber esses refugiados, surge uma maior motivação para a instauração do ACNUR em território nacional, sendo oficialmente inaugurado no Brasil em 1982.

No entanto, ainda havia um problema. Ao aderir à convenção de 1951, os dispositivos estabelecidos no Brasil entendiam como refugiados apenas as populações provenientes do continente europeu, de forma que ainda era necessário que o ACNUR buscasse novos diálogo com o governo, para eliminar a chamada reserva geográfica e passar a entender e receber pessoas de qualquer lugar do mundo como refugiados, respeitando as limitações estabelecidas na classificação, mas recusando a premissa de origem geográfica.

Foram elaborados os conceitos fundamentais acerca dos refugiados para os países da América Latina com a Declaração de Cartagena de 1984, especialmente na esfera dos direitos humanos. Uma das importantes medidas adotadas foi a amplificação do conceito de refugiado, que passou a ter como elemento a violação de direitos humanos, conforme descrito na Convenção de 1951 e no Protocolo de 1967.

Importante destacar que a amplificação do conceito de refugiados era necessária, tendo em vista a doutrina mencionada nos relatórios da Comissão Interamericana dos Direitos humanos e da Convenção da Organização da União Africana, OUA. 
A Declaração de Cartagena passou a fazer parte efetivamente do ordenamento jurídico no Brasil, desde a promulgação da Constituição Federal de 1988, tendo influenciado a Carta Magna, especialmente no que tange à dignidade da pessoa humana e à prevalência dos direitos humanos. Houve, portanto, uma observância por parte da Constituição Federal da Declaração de Cartagena, o que derrubou os obstáculos para a efetivação dos princípios presentes na Declaração através do advento da Lei no 9.474/97 (BARRETO; LEÃO, 2010, p. 127).

Muito importante durante a redemocratização do Brasil, a eliminação da já citada reserva geográfica sobre a Convenção de 1951 ocorreu por meio do Decreto $\mathrm{n}^{\circ}$ 98.602, passando o Brasil a receber os refugiados de qualquer lugar do mundo. Isso permitiu o ingresso de muitos refugiados africanos, principalmente os angolanos e os liberianos. Este decreto, promulgado em 1989, significou uma adesão mais plena à Declaração de Cartagena e abriu ainda mais as fronteiras do país para que refugiados fossem recebidos.

Também nesse contexto houve uma retomada do assunto no Brasil, considerando-se que o cuidado com os direitos humanos ajudou para os progressos feitos a partir de 1984 como fundamentos de uma nova política brasileira.

O decreto é ainda complementado em 1991, período em que o número de refugiados no país ainda era muito baixo, com a edição da portaria interministerial n0394, editado pelo Ministério da Justiça. Com esta portaria são estabelecidos dispositivos jurídicos mais eficientes para proteger os refugiados recebidos em território nacional, estabelecendo novas dinâmicas para os processos de solicitação e concessão de refúgio para aqueles que necessitavam.

Durante o governo de Fernando Henrique Cardoso foram adotadas duas importantes medidas de proteção dos refugiados, quais sejam: a Declaração de San José sobre refugiados e pessoas deslocadas, em 1994, e a Lei n 9.747 de 22 de julho de 1997.

Por meio da edição da Lei no. 9.747, que possui um total de 49 artigos, estabeleceu-se como um novo mecanismo para que o Estatuto dos Refugiados pudesse ser efetivamente implementado na legislação brasileira. 
Esta Lei, redigida por meio de uma parceria entre Estado, sociedade civil e o ACNUR configura uma das leis mais modernas, abrangentes e generosas existentes no mundo, status reconhecido pela própria Organização das Nações Unidas. A qualidade desta Lei se estabelece por ser um dispositivo completo, que compreende a proteção internacional dos refugiados ao mesmo tempo em que estabelece a criação do Comitê Nacional para os Refugiados, o CONARE, como órgão nacional responsável por resguardar as políticas públicas em prol desses indivíduos, sendo ainda o órgão que toma a decisão final sobre o acolhimento ou não das solicitações de refúgio no Brasil.

A Declaração de San José atualiza, reitera e amplia o âmbito de aplicação da Declaração de Cartagena, ao enfatizar a importância dos direitos humanos dos refugiados e das pessoas deslocadas internamente na América Latina e no Caribe, incluindo os movimentos migratórios forçados. Ademais, essa Declaração destaca a importância do aspecto de gênero, de populações indígenas, de crianças e de emigrantes, sendo todas titulares de direitos que precisam ser observados sempre (CUNHA, 1998, p. 66).

A Lei Federal n 9.474 é uma das normas mais avançadas, tendo sido aprovada depois de aprovação do Projeto de Lei n 1.936/96 no Congresso Nacional, elaborado com a ajuda do ACNUR. Isso ocorreu, principalmente, em virtude da pressão desempenhada pela sociedade civil organizada, especialmente a Igreja Católica (MOREIRA, 2007; LEÃO, 2004).

Como afirma Moreira (2007, p. 18), "o arranjo institucional do CONARE consolida a estrutura tripartite que já estava sendo montada desde meados de 1970 no Brasil, reunindo os principais atores em relação aos refugiados: a sociedade civil organizada doméstica, o governo e o ACNUR".

Em 2007 foi elaborado o Comitê Estadual para os Refugiados de São Paulo (CER), que teve como objetivo propagar as políticas de inclusão social e de assistência, dando aos refugiados a tutela de seus direitos. Nesse contexto, seguindo Moreira (2007, p. 23), o Brasil vem se destacando pela sua atuação frente aos refugiados. O ACNUR o considera um líder regional nessa matéria, com capacidade de ajudar a prevenir a intensificação de conflitos na região que possam resultar em 
novos fluxos. Como pontua Sampaio (2010) existem diversas políticas públicas que não beneficiam os refugiados porque seus mecanismos de acesso desconhecem esta condição jurídica. Questões como o acesso à moradia popular, benefício de prestação continuada, validação de diplomas e participação em concursos públicos, tropeçam em entraves burocráticos ou mesmo normativos, em sua maioria, pautados pelo desconhecimento e insipiência do ordenamento jurídico referente ao refúgio no Brasil.

\section{DIREITOS HUMANOS E CONSTITUIÇÃO FEDERAL DE 1988}

A Declaração Universal de Direitos Humanos quanto os demais dispositivos internacionais e internos, fazem com que os Estados membros tenham como obrigação principal cumprir e fazer cumprir as normas de direitos humanos estabelecidas, inclusive inserindo em sua normatização legal estatutos que permitam que tal finalidade seja alcançada.

Por este motivo, muitos países, através de ratificação de tratados internacionais, absorveram em suas constituições diversos dispositivos que buscam respeitar, fazer cumprir e promover os direitos humanos em seus variados aspectos.

As constituições nacionais são instrumentos políticos e jurídicos que assentam a estrutura de um Estado, tratam acerca do seu funcionamento, sistema de governo, formação dos tribunais entre outras disposições. Daí a importância e, até mesmo, o simbolismo dessas legislações, uma vez que carregam como significado um processo de nacionalização dos direitos humanos, acomodando, não só no seio social, mas na própria estrutura estatal, os dispositivos de direitos humanos que foram debatidos, estudados e motivos de consensos entre várias nações.

Com isso, ferramentas concretas passam a ficar disponíveis aos administrados para rechaçar comportamentos totalitários e abusivos, inclusive do próprio Estado. No entanto, não é suficiente somente a disponibilização de meios para coibir tais ações, pois é necessário a promoção dos direitos humanos e a 
inserção na cultura local, para evitar que eventuais mudanças de governo ou regime possam cessar ou inviabilizar possíveis avanços.

O reconhecimento dos direitos humanos, bem como a sua inserção no sistema jurídico do Brasil, tem início e se mantém, atualmente, disseminado na carta política da nação: a Constituição de 1988. Todavia, ainda que presentes ao longo de todo o documento, os chamados direitos e garantias fundamentais se encontram mais bem expressos e representados como tema no artigo $5^{\circ}$ da Carta. Conforme define José Silva (2002, p. 178), tais direitos são uma limitação imposta pela soberania popular aos poderes constituídos do Estado que dela dependem.

No Brasil, com o fim do regime militar, que cassou os direitos políticos, ganharam relevo com a Carta de 1988. Assim, após um longo período sem garantias, uma Assembleia Nacional Constituinte promulgou a atual Constituição da República Federativa do Brasil, mais especificamente em 05 de outubro de 1988, que estabeleceu, dentre vários dispositivos, cláusulas consideradas pétreas.

As cláusulas pétreas inseridas na Constituição do Brasil de 1988 estão dispostas em seu artigo 60, § 40. São elas: a forma federativa de Estado; o voto direto, secreto, universal e periódico; a separação dos Poderes; e os direitos e garantias individuais (BRASIL, [2016]).

No entanto, como herança desse período de repressão, as violações aos direitos, sobretudo aos individuais, são constantes, geralmente por parte do próprio Estado, motivo pelo qual a conscientização acerca das garantias fundamentais é crucial para tornar a sociedade articulada para se proteger exigir reparação pelos danos causados.

No que concerne aos direitos humanos, entendidos na Constituição, como mencionados, como componentes do gênero de direitos e garantias fundamentais é tema bastante amplo e que, de acordo com grande parte dos doutrinadores, começou a ser discutido ainda na antiguidade, amparado pelo direito natural.

Portanto, de tão importante para a estrutura do Estado que são os direitos e garantias fundamentais, os constituintes consignaram no inciso IV, §40, do artigo 60 da Constituição da República Federativa do Brasil (BRASIL, [2016]) que a proposta que tende a abolir as referidas garantias não será sequer objeto de deliberação. 
De forma abrangente 0 artigo $5^{\circ}$ Constitucional estabelece critérios gerais de igualdade e considera invioláveis a vida, liberdade, segurança e propriedade, porém, é bastante comum a violão destes dispositivos.

Sobre o caráter protetor dos direitos humanos na Constituição Federal, Piovesan (2012, p. 75) afirma que ao romper com a sistemática das Cartas anteriores, a Constituição de 1988, ineditamente, "consagra o primado do respeito aos direitos humanos, como paradigma propugnado para a ordem internacional. Esse princípio invoca a abertura da ordem jurídica interna ao sistema internacional de proteção dos direitos humanos."

A partir do momento em que o Brasil se propõe a fundamentar suas relações internacionais com base na prevalência dos direitos humanos, ainda seguindo Piovesan (2012, p. 75) "está ao mesmo tempo reconhecendo a existência de limites e condicionamentos à noção de soberania estatal, do modo pelo qual tem sido tradicionalmente concebida". Isto é, a soberania do Estado brasileiro fica submetida a regras jurídicas, tendo como parâmetro obrigatório a prevalência dos direitos humanos. Surge, pois, a necessidade de interpretar os antigos conceitos de soberania nacional e não-intervenção à luz de princípios inovadores da ordem constitucional; dentre eles, destaque-se o princípio da prevalência dos direitos humanos. Esses são os novos valores incorporados pelo Texto de 1988 e que compõe a tônica do constitucionalismo contemporâneo.

Além disso, este processo de inserção de direitos fundamentais na Constituição se coloca, ainda, como elemento de inovação que amplia direitos e garantias dos indivíduos, não se limitando a direitos políticos e civis, mas considerando, também, direitos relacionados a aspectos sociais.

O destaque e importância deste fato se deve a inédita aparição de declarações relacionadas a direitos sociais em uma constituição brasileira, uma vez que as versões anteriores dessa Carta tomavam conhecimento de direitos humanos apenas do ponto de vista da ordem econômica e social relacionadas a direitos específicos, não possuindo títulos voltados especificamente para os direitos humanos e formas de oferecer garantias de sua manutenção. 
Na Constituição Federal de 1988 estão presentes tanto o princípio da indivisibilidade e interdependência dos direitos humanos individuais, que estabelecem que liberdade e igualdade são valores que se associam, de forma que são direitos que não podem ser garantidos separadamente, quanto os direitos chamados de coletivos e difusos, sendo os coletivos aqueles destinados a classes sociais ou categorias, enquanto os difusos são pertinentes a todos, sem categorias estabelecidas.

Desta maneira, como destaca Piovesan (2012, p. 78): "a Carta de 1988, ao mesmo tempo em que consolida a extensão de titularidade de direitos, acenando para a existência de novos sujeitos de direitos, também consolida o aumento da quantidade de bens merecedores de tutela, por meio da ampliação de direitos sociais, econômicos e culturais". Desta forma, os direitos e garantias fundamentais passam a ser dotados de uma especial força expansiva, projetando-se por todo o âmbito constitucional e servindo como critério interpretativo de todas as normas do ordenamento jurídico nacional.

Vê-se que ao estabelecer formas de garantir a inalienabilidade dos direitos humanos por meio da Constituição Federal de 1988 frisou-se um empenho na busca por maior igualdade e liberdade no Brasil, oferecendo melhores condições de garantir aos cidadãos condições básicas de sobrevivência e ferramentas para que o próprio Estado seja cobrado em suas responsabilidades.

\section{OS MOVIMENTOS MIGRATÓRIOS E O REFÚGIO}

Com o fim da Guerra Fria, quando ocorreram muitas mudanças econômicas, sociais e políticas ao redor do mundo, o cenário econômico passou a ser representado pelo neoliberalismo e pela formação de blocos econômicos. Após a recessão econômica é que os refugiados passaram a ser vistos de maneira depredatória, pois eles não davam benefícios aos países desenvolvidos (FELLER, 2001, p. 89). Por conseguinte, consoante mencionado por Hyndman (2000, p. 76), os refugiados, depois do fim da Guerra Fria, perderam o simbolismo político que tinham em tal período. 
Hoje, grande parte dos deslocamentos ocorre em razão das desigualdades sociais ainda muito profundas em alguns países, considerando-se que a miséria geralmente está conectada com perseguições religiosas e políticas. É comum que em tempos de crise, seja qual for a sua natureza, ocorra muita xenofobia, discriminação e racismo.

Há nas sociedades uma notória turbulência política, social e econômica, de maneira que os fatos que envolvem determinados estratos sociais são acentuados e os atingidos são geralmente os mais debilitados socialmente.

Nesse sentido os direitos humanos ganham maior destaque devido ao alcance dos seus institutos, que têm como desafio versar sobre questões relativas a toda e qualquer sociedade. $\mathrm{O}$ estabelecimento dos direitos humanos como institutos supraestatais contribuiu para destacar a importância do debate e reflexão sobre práticas voltadas para a proteção da vida e da dignidade humana e leva os países a inserirem em suas constituições dispositivos para cumprir esse mister.

A busca por refúgio, que se dá por motivos diversos, é um fenômeno político, na medida em que a ausência de disposição governamental atira pessoas para situação de risco e faz com que estas deixem seus países de origem em direção a outro onde imaginam que possam viver melhor, ou pelo menos sem risco de morte.

Dados mais recentes da Agência da Organização das Nações Unidas para Refugiados (UNITED NATIONS HIGH COMMISSIONER FOR REFUGEES, 2016) mostram que entre o total da população refugiada em todo o mundo, $51 \%$ são crianças e adolescentes e que os refugiados são de países periféricos e semiperiféricos. Essa circunstância decorre da maior vulnerabilidade desses países nos aspectos políticos, econômicos, sociais, por causa disso, os direitos humanos ou mesmo garantias fundamentais são ignorados ou sequer existem.

Percebe-se que as políticas públicas voltadas para pessoas em situação de refúgio não são suficientes para evitar ou atenuar efeitos deletérios que atingem os refugiados, que são exploração, inclusive a sexual, abusos, prostituição, tráfico de pessoas, racismo, preconceito e rejeição. 
Mesmo com os esforços de Estados e de entidades públicas e privadas, as pessoas em situação de refúgio padecem de diversas mazelas e isso ocorre por ausência de políticas governamentais efetivas e alinhadas à normatização dos organismos internacionais.

As pessoas em situação de refúgio que deixam de ser recepcionadas adequadamente e amargam situação de intolerância tem as suas adversidades aprofundadas, o que acaba atingindo o meio que escolheram para refugiar-se, porque há consequências deletérias do refúgio.

É necessário destacar que os refugiados forçados ao se deslocarem pelo espaço internacional se definem por estar em uma condição geopolítica de mobilidade que, de acordo com Hyndman (2000, p. 50-53), há assimetria nas relações entre os seres humanos os fluxos populacionais e os movimentos migratórios.

As fronteiras são entendidas por grande parte da população como uma área para passagem de um país para o outro, sem filtros e sem restrições, mas para outras como porta fechada difíceis de serem abertas e ultrapassadas.

Desta maneira, os direitos humanos acabam sendo deixados de lado e a dignidade humana submetida às decisões arbitrárias de governos com base em etnias, religiões e diversos outros elementos que não deveriam ser utilizados para a exclusão de indivíduos.

Segundo Andrade (1996b), tendo em vista esse panorama socioeconômico e cultural, a fim de tentar solucionar o problema dos refugiados, destacam-se três soluções a serem adotadas, quais sejam, a integração local, que significa o acolhimento do refugiado pelo país em que a pessoa escolheu para viver, a repatriação voluntária, que é aquela na qual o indivíduo refugiado é enviado novamente para o seu país de origem, e o reassentamento, que é o procedimento por meio do qual um terceiro país acolhe a pessoa refugiada.

Dentre as três soluções acima mencionadas, a repatriação voluntária acaba sendo a mais complicada, tendo em vista que as pessoas sempre acabam querendo voltar aos seus países de origem, pois nesses locais elas encontram a sua cultura. Contudo, esse é um caminho complicado, em virtude das violações de direito que 
ocorrem nos locais de origem, dificultando o retorno das pessoas aos seus lares, especialmente se ainda existirem resquícios de conflitos internos (ANDRADE, 1996b, p. 37).

Já a integração com o local escolhido pelo refugiado acaba sendo uma solução mais comum, apesar de também ser bem complicada em razão da adaptação pela qual o indivíduo terá que passar em um local estranho, o qual simboliza para ele uma nova cultura, tanto de hábitos quanto de tradições, diferente daquela que representa o seu país de origem (ANDRADE, 1996b, p. 38).

O reassentamento, por fim, é uma solução geralmente procurada quando existe perigo à integridade física do refugiado, pelos mais diferentes motivos, e também quando ele não consegue se adaptar a um determinado país, sendo necessário o seu redirecionamento a outro local (ANDRADE, 1996b, p. 41).

Enfim, existem muitos vieses pelos quais a situação de um refugiado pode ser considerada, tendo em vista um contexto socioeconômico e cultural de um determinado país. Entretanto, torna-se essencial que os países, de uma forma geral, passem a tratar do assunto de maneira mais cautelosa, especialmente porque os deslocamentos humanos são atualmente um problema político de fundamental importância, que interfere de modo determinante nas relações políticas entre as nações do planeta.

\section{CONSIDERAÇÕES FINAIS}

Como pontua Bonavides (1998, p. 71) "com maior frequência são a miséria e a carência de perspectivas de desenvolvimento que impelem indivíduos e famílias ao exílio, a fim de procurarem modo de sobrevivência em terras distantes, onde não é fácil encontrar boas condições de acolhida".

Diversos fatores fazem com que um povo precise se locomover e mudar de vida de forma forçada. Guerras e perseguições sempre foram as mais comuns. As violações dos direitos humanos no país de origem fazem com que muitos busquem ajuda atravessando fronteiras em busca de segurança e utilizando de recursos internacionais, como à Organização das Nações Unidas, ONU. 
Os casos de conflitos acabam colocando em perigo grupos de pessoas que têm etnias minoritárias ou opiniões políticas diferentes dos demais. Outro importante fator de migração é a situação econômico-financeira, em virtude de diminuição do status social nos países de origem, além dos aspectos ambientais que contextualizam o problema das pessoas nessa situação.

A questão dos refugiados é de grande relevância no cenário mundial e tem sido cada vez mais expressiva como um tema de preocupação internacional, devido ao grande fluxo de imigrações que vem ocorrendo. Junto a esse fluxo, vem também o descontentamento de grandes potências e as tentativas de contenção de imigrantes, além de diversos casos de violência contra refugiados.

As conclusões indicam que ao contrário de alguns movimentos políticos que rejeitam os refugiados este estudo aponta em sentido oposto, o de aprofundar políticas públicas, seja por questão humanitária ou para evitar crises sociais diante pela não inserção social dessas pessoas.

Nem sempre a chegada ao país de refúgio garante a tão buscada segurança. Isso porque além de medidas restritivas de grandes potências, já supracitadas, há também barreiras ligadas ao preconceito com outros povos, principalmente em países nos quais a miscigenação de povos é algo recente ou, pior, não é bem-vinda.

A garantia dos direitos humanos dos refugiados é um grande desafio, que deve ser enfrentado.

\section{REFERÊNCIAS}

ALTO COMISSARIADO DAS NAÇÕES UNIDAS PARA REFUGIADOS. A situação dos refugiados no mundo: cinquenta anos de acção humanitária. Almada: $A$ Triunfadora Artes Gráficas, 2002.

ANDRADE, José Henrique Fischel de. O Brasil e a Proteção de Refugiados: a discussão tem início no Congresso Nacional. Pensando o Brasil, v. 5, n. 16, p. 712 , set. $1996 \mathrm{~b}$.

ANDRADE, José Henrique Fischel de. A proteção internacional dos refugiados no limiar do século XXI. Travessia-Revista do Migrante, São Paulo, p. 37-42, maio/ago. 1996b. 
BARRETO, Luiz Paulo T.; LEÃO, Renato Zerbini Ribeiro. O Brasil e o espírito da Declaração de Cartagena. Revista Forced Migration, [São Paulo], 35. ed., p. 1-2, jul. 2010.

BRASIL. [Constituição (1988)]. Constituição da República Federativa do Brasil de 1988. Brasília, DF: Presidência da República, [2016]. Disponível em:

http://www.planalto.gov.br/ccivil_03/Constituicao/ Constituiçao.htm. Acesso em: 18 jan. 2016.

BRASIL. Secretaria Nacional de Justiça. Departamento de Justiça, Classificação, Títulos e Qualificação. Coordenação de Enfrentamento do Tráfico de Pessoas. Tráfico de pessoas: uma abordagem para os direitos humanos. Organização: Fernanda Alves dos Anjos et al. Brasília, DF: Ministério da Justiça, 2013.

BONAVIDES, Paulo. A quinta geração de direitos fundamentais. Direitos fundamentais \& justiça, Porto Alegre, v. 2, n .3, p. 82-93, 2008.

CUNHA, Guilherme L. da. Migrações, Direitos Humanos e Direito de Asilo. In: BAPTISTA, Luiz Olavo; FONSECA, José Roberto Franco da. O direito internacional. 2. ed. São Paulo: LTr, 1998.

DOMINGUEZ, Juliana Arantes; BAENINGER, Rosana. Programa de reassentamento de refugiados no Brasil. [Brasília, DF]: Instituto de Migrações e Direitos Humanos, 2007. Disponível em: http://www.migrante.org.br/textoseartigos.htm. Acesso em: 3 mar. 2016.

FELLER, Erika. The Convention at 50: the way ahead for refugee protection. Forced Migration Review, Oxford, n. 10, p. 6-9, abr. 2001. Disponível em: http://www.fmreview.org/FMRpdfs/FMR10/fmr10.3.pdf. Acesso em 27 de ago. 2009.

HYNDMAN, Jennifer. Managing displacement: refugees and the politics of humanitarianism. Minnesota: University of Minnesota Press, 2000.

LEÃO, Renato Zerbini Ribeiro. O instituto do refúgio no Brasil após a criação do Comitê Nacional para os Refugiados - Conare. Revista do Instituto Brasileiro de Direitos Humanos, Fortaleza, v. 5, n. 5, p. 1-19, abr./jun., 2004.

MOREIRA, Julia Bertino. O acolhimento os refugiados no Brasil: políticas, frentes de atuação e atores envolvidos. In: ENCONTRO NACIONAL SOBRE MIGRAÇÕES, 5., 2007, Campinas. Anais [...]. Campinas: [s.n.], 2007.

PIOVESAN, Flávia. Temas de Direitos Humanos. 5. ed. São Paulo: Saraiva, 2012.

SAMPAIO, Cyntia. Programa brasileiro de reassentamento solidário: evolução e reflexões para seu fortalecimento. Cadernos de Debates Refúgio, Migrações e Cidadania, Brasília, DF, v. 5, n. 5, p. 19-39, 2010. Disponível em: 
http://www.acnur.org/t3/fileadmin/Documentos/portugues/

Publicacoes/2011/Caderno_de_Debates_5.pdf? view=1. Acesso em 4 mar. 2013.

SARAIVA, José Flávio Sombra. Dois gigantes e um condomínio: da Guerra Fria à coexistência pacífica. In: SARAIVA, José Flávio Sombra (org.). Relações

internacionais contemporâneas: da construção do mundo liberal à globalização (de 1815 a nossos dias). Brasília: Paralelo 15, 1997. p. 241-278.

SILVA, José Afonso da. Curso de direito constitucional positivo. 20 ed. São Paulo: Malheiros, 2002.

SILVA, César A. S. Os regimes internacionais para refugiados e a situação brasileira. São Francisco da Serra: Centro de Investigação e Análise em Relações Internacionais (Ciari), 2011.

UNITED NATIONS HIGH COMMISSIONER FOR REFUGEES. Global trends forced displacement in 2015. Geneva: UNHCR, 2016. Disponível em: http://www.unhcr.org/statistics/unhcrstats/576408cd7/unhcrglobal-trends-2015.html. Acesso em: 15 ago. 2016. 